\title{
Factors associated with the failure of first and second-line antiretroviral therapies therapy, a case control study in Cambodian HIV-1 infected children
}

Hubert Barennes ${ }^{1,2,3,4^{*}}$, Kang Virak ${ }^{2}$, François Rouet ${ }^{5}$, Yves Buisson $^{2}$, Michel Strobel $^{2}$ and Ung Vibol ${ }^{6}$

\begin{abstract}
Background: Little is known about the efficacy of first and and second-line antiretroviral therapies (ART) for HIV-1 infected children in resource limited Southeast Asian settings. Previous studies have shown that orphans are at a higher risk for virological failure (VF) in Cambodia. Consequently most of them required transfer to second-line ART. We assessed the factors associated with VF among HIV-1 infected children who were either under first-line (mostly $3 T C+D 4 T+N V P$ ) or under second-line (mostly ABC + DDI + LPV) therapies at a referral hospital in Cambodia.
\end{abstract}

Methods: A case-control study was conducted from February to July 2013 at the National Pediatric Hospital among HIV-1 infected children (aged 1-15 years) under second-line ART (cases) or first-line (matched controls at a ratio of 1:3) regimens. Children were included if a HIV-1 RNA plasma viral load (VL) result was available for the preceding 12 months. A standardized questionnaire explored family sociodemographics, HIV history, and adherence to ART. Associations between VF (HIV-1 RNA levels $\geq 1000$ copies/ml) and the children's characteristics were assessed using bivariate and multivariate analyses.

Results: A total of 232 children, 175 (75.4\%) under first-line and 57 (24.6\%) under second-line ART, for a median of 72.0 (IQR: 68.0-76.0) months, were enrolled. Of them, 94 (40.5\%) were double orphans and 51 (22.0\%) single orphans, and 77 (33.2\%) were living in orphanages. A total of 222 children (95.6\%) were deemed adherent to ART. Overall, 18 (7.7 \%; $95 \%$ Cl 4.6-11.9) showed a VF, 14 (8.6\%; $95 \%$ Cl 4.8-14.0) under first-line and 4 (7.0\%; $95 \%$ Cl 1.9-17.0) under second-line ART $(p=0.5)$. Their median CD4 percentage was $8 \%$ (IQR 2.9-12.9) at ART initiation. Children under second-line ART were older; more often double orphans, and had lower CD4 cell counts at the last control.

In the multivariate analysis, having the last CD4 percentage below $15 \%$ was the only factor associated with VF for ART regimen separately or when combined (OR 40.4; $95 \% \mathrm{Cl} 11-134)$.

Conclusions: The pattern of risk factors for VF in children is changing in Cambodia. Improved adherence evaluation and intensified monitoring of children with low CD4 counts is needed to decrease the risk of VF.

Keywords: AIDS, Antiretroviral therapy, Cambodia, Children, CD4, HIV, Low income countries, NCHADS, Orphans, Virological failure

\footnotetext{
*Correspondence: barenneshub@yahoo.fr

${ }^{1}$ Agence Nationale de Recherche sur le VIH et les Hépatites, Preah

Monyvong Blvd, Phnom Penh, Cambodia

Full list of author information is available at the end of the article
} 


\section{Background}

By the end of 2013, of the 35.3 million people living with HIV in the world, 3.3 million were children. Improved access to services for prevention of mother-to-child transmission of HIV and improved availability of antiretroviral therapy (ART) have reduced the number of new HIV infections by $50 \%$ and AIDS-related deaths by $20 \%$ among children [1].

The number of children, less than 15 years, receiving ART in low-and middle-income countries increased from 566,000 in 2011 to 630,000 in 2012 but this increase remains far below that of adult patients [2,3]. An estimated 200,000 children with HIV live in Southeast Asia. Of them, 46,000 (23\%) receive ART, 21,000 were newly infected and 13,000 died in 2012 [4]. Good ART outcomes have been reported from pediatric HIV/AIDS programs in low resource settings, comparable to those in high-income countries [5].

Children on ART pose crucial concerns in low resources settings $[4,5]$. First, they require long-term therapy with unknown long-term side effects. Second, the scarcity of pediatric formulations and inadequate dosage guidelines for specific antiretrovirals (ARVs) and age groups may contribute to suboptimal plasma drug levels. Third, these children, especially teenagers, have decreased adherence to treatment. All these factors can result in rapid HIV drug resistance (HIV DR).

Children are twice as likely to experience virological failure (VF) to ART as compared with adults after 5 years of treatment and $13-53 \%$ of them are expected to experience VF within the first year [6]. Therefore, they are at a higher risk of developing HIV DR, particularly if failure is diagnosed late [7]. HIV DR genotyping has become a standard of care in HIV infection management in developed countries [6] but its availability remains infrequent in the developing world [8].

Over the last decade, Cambodia's human immunodeficiency virus (HIV) program (NCHADS, National Center for HIV/AIDS, Dermatology and STD, Sexually Transmitted Diseases) has been quite successful. The prevalence of HIV infection decreased from $2.4 \%$ in 1998 to $0.7 \%$ in $2012[9,10]$. The number of children living with HIV was estimated at 8512 and 4052 (47.6\%) were under ART in $2013[9,11,12]$.

Several studies have reported the high effectiveness of ART in Cambodia for durations ranging from 12 to 36 months [13-15]. Compared to ART children, preART children have a 4:1 mortality ratio and a 13:8 ratio of loss to follow-up $[14,15]$. Being an orphan was considered an important predictor of VF [13].

Data on pediatric treatment monitoring and resistance in first-line and second-line failures are limited in Cambodia. Based on the WHO 2010 pediatric guidelines, without routine viral load monitoring, treatment failure were misclassified for children on first-line therapy $[16,17]$. In addition, extensive drug resistance to first-line ART was described among 51 HIV-infected children, who were undetected as first-line ART failures under the WHO 2010 guidelines [18]. Similarly the HIV/Hepatitis laboratory of the Pasteur Institute in Cambodia reported the occurrence of mutations in children from routine samples collected between December 2004 and January 2011 [17]. Since then, children were switched to second-line ART primarily based on clinical and immunological criteria, following national pediatric guidelines [19]. This is the first study to compare the current profile of children under first-line and second-line ART in Cambodia and to assess the evolution of factors associated with VF in a pediatric referral hospital.

\section{Methods}

\section{Ethics statement}

The study was authorized by the National Pediatric Hospital (NPH) authorities. Ethical approval was granted by the Cambodian and Lao Medical Ethics Committees because the study was conducted in Cambodia as part of a master study from the "Institut de la Francophonie pour la Médecine Tropicale" (IFMT, Vientiane, Laos). The study complied with the Cambodian law on personal protection of people living with HIV. Children and parents/guardians were informed about the study in Khmer language and given an information paper describing it. They were included if they consented to participate and if their parent/guardians gave informed consent in writing. Confidentiality was guaranteed and interviews were conducted by a clinical investigator in a private room. Attention was paid to not disclosing the reason for the visit, or the child's status, during home visits. Data was recorded anonymously.

\section{Study site}

The study was conducted from February to July 2013 in the HIV clinic of the NPH in Phnom Penh during children's routine visits. The NPH was the first setting to start ART in 2004. At the time of the study NPH provided ART to 1300 HIV children, including 107 on second-line ART. Children were monitored every 3 months at the outpatient department for clinical status, adherence and counseling and CD4 cell counts.

Plasma HIV-1 viral load (VL) was measured according to the Cambodian National Guidelines for Management of Pediatric HIV recommendation once within the first 6 months of starting ART and then every 12 months. HIV-1 genotyping was not routinely available for children. 


\section{Study procedures and questionnaires}

Cambodian children between 12 months and 15 years attending the HIV clinic were eligible if they had been under second-line ART for at least 6 months and if VL had been performed after the start of second-line line and within the 12 months prior to the survey. For each child on second-line ART, 3 children on first-line ART and of a similar age \pm 1 years and with a VL conducted within the last 12 months were randomly selected among those attending the clinic the same day.

An interview was conducted with the parent/guardian and child in Khmer language. The questionnaire included sociodemographic items about the household, parental resources (if available), access to care and compliance with ART (Additional file 1).

For children younger than 7 years, the parent/guardians were asked questions. Children over 7 years old were asked these questions directly in the presence of their parent/guardian.

Data relating to the child's HIV status, disease history and treatment was retrieved from the hospital records after the interview. Adherence to treatment was evaluated by the recall of missed medication intake during the previous 4 days, within the previous month and by counting the tablets at home. The tablet counting was performed after parental agreement, on appointment with parent/caregivers within 1 month after the first meeting. Adherence variables were dichotomized as complete $(100 \%)$ vs. incomplete $(<100 \%)$ [20].

\section{Definitions}

Single orphans were children who had lost one parent and double orphans were children who had lost both.

Virological failure was defined as plasma HIV-1 RNA level $\geq 1000$ copies $/ \mathrm{mL}$. For children on second-line therapy, the VL had to be done after the start of second-line treatment in order to be considered as second-line failure $[21,22]$. Due to limited resources and NPH procedures VL was not tested a second time.

\section{Sample size}

Using Stata Version 8 (Stata Cooperation, College Station, TX), a required sample size of 250 people was calculated using a 1:3 ratio between second-line and first-line children. Based on previous reports of effectiveness of first-line ART and an estimate of current VF on secondline (unpublished data), VF was expected around $6 \%$ among second-line ART children and $25 \%$ among firstline ART children. The sample size was adapted by estimating the number of second-line treatment patients attending the clinics over 4 months that could be enrolled (i.e.: $40-60$ patients). with $10 \%$ precision, alpha $=0.05$, power $90 \%$.

\section{Data management and analysis}

Data was entered in Epidata freeware (http://www.epidata.dk, Odense, Denmark) and cross-checked against original data sheets. Analyses were carried out with Stata software, Version 8 (Stata Corporation, College Station, TX, USA). $\mathrm{Chi}^{2}$ or Fisher's exact test were used to assess associations between categorical variables as appropriate, and Student's $t$ test for two normally distributed continuous variables or Kruskal-Wallis as appropriate. $\mathrm{P} \leq 0.05$ was considered significant. Associations between VL and children's characteristics were initially measured using bivariate analyses (age, sex, socio-economic conditions, schooling, time since diagnosis and ART, and adherence to treatment, initial CD4 cells count, type of treatment and weight gain over the preceding year).

Multivariate analyses between VL and children's characteristics were conducted initially for each treatment group, then combining both treatment groups, by introducing into the model the variables significantly associated with VL (those with $p$ values $<0.2$, Tables 1,2 ). Then, a back-step selection procedure using odd ratios was used to leave only those with a $p$ value $<0.05$ in the final model.

We have attempted to report the study according to the STROBE guidelines (Additional file 2).

\section{Results}

\section{Characteristics of the study population}

A total of 250 children (63 and 187 on second-line and first-line, respectively) were eligible for the survey. Of these, 232 (92.8\%) had VL recorded within the last 12 months and were analyzed including 175 (75.4\%) on first-line and 57 (24.6\%) on second-line ART (Fig. 1).

A total of 157 (62\%) children had a VL done during the survey including 37 (58.7\%) second-line and 120 (64.1\%) first-line. The median time between VL and survey assessment was 4.0 months (inter quartile range: $3-5$ ).

Their social and treatment characteristics are shown in Tables 1 and 2, and supplementary tables.

Among them, 94 (40.5\%) were double orphans, 51 (22.0\%) single orphans and 77 (32.2\%) lived in orphanages. A total of 79 children (34.1\%) were cared for by their mothers, while $61(27.6 \%)$ by another member of the family, and 89 (38.4\%) by non-family. The median time on ART was shorter for children of the first-line group vs. for children of the second-line group (70.5 [43.9-90.8] months and 81.0 [71.4-92.5] months respectively, $\mathrm{p}=0.001)$. The majority were WHO Stage II $(\mathrm{N}=129,55.6 \%)$ and the median $\mathrm{CD} 4$ percentage in all patients was $8 \%$ (IQR 2.9-12.9), at initiation of ART (Supplementary table). The median interval between diagnosis and ART onset was 11.8 (IQR 9.4-14.2) 
Table 1 Socio-demographic characteristics of children on first-line and second-line ART at National Pediatric Hospital

\begin{tabular}{|c|c|c|c|c|c|}
\hline & \multicolumn{2}{|l|}{ First-line } & \multicolumn{2}{|l|}{ Second-line } & \multirow[t]{2}{*}{$\mathbf{p}$} \\
\hline & $n=175$ & $\%$ & $n=57$ & $\%$ & \\
\hline Female & 91 & 52.0 & 24 & 42.1 & 0.1 \\
\hline Age median, years & 11.4 (IQR: 9.2-13.5) & & 11.4 (IQR: 9.4-13.8) & & 0.4 \\
\hline Age up to 7 years & 151 & 86.3 & 56 & 98.2 & 0.01 \\
\hline Orphan both parents & 65 & 37.1 & 29 & 50.9 & 0.06 \\
\hline Orphan mother & 10 & 5.7 & 2 & 3.5 & 0.3 \\
\hline Orphan father & 31 & 17.7 & 8 & 14.0 & \\
\hline Living in orphanage & 50 & 28.6 & 27 & 47.4 & 0.009 \\
\hline \multicolumn{6}{|l|}{ Child education } \\
\hline Not attending school ( $>5$ years. $n=219$ ) & 6 & 3.4 & 0 & 0.0 & \\
\hline Primary & 106 & 60.6 & 43 & 75.4 & 0.2 \\
\hline Secondary & 46 & 26.3 & 12 & 21.1 & \\
\hline Father low skilled worker $(n=191)$ & 60 & 34.3 & 12 & 21.1 & \\
\hline Mother low skilled $(n=126)$ & 60 & 47.6 & 15 & 26.3 & \\
\hline \multicolumn{6}{|l|}{ In charge of the child } \\
\hline Mother & 78 & 44.6 & 23 & 40.4 & 0.3 \\
\hline Father & 6 & 3.4 & 1 & 1.8 & \\
\hline Grandmother & 24 & 13.7 & 5 & 8.8 & \\
\hline Relatives & 3 & 1.7 & 0 & 0.0 & \\
\hline Others $^{\mathrm{a}}$ & 64 & 36.6 & 28 & 49.1 & \\
\hline \multicolumn{6}{|l|}{ Family assets and characteristics } \\
\hline Own their house $(n=149)$ & 87 & 58.4 & 18 & 31.6 & 0.2 \\
\hline Number of people living in same house & 5.1 & 3.3 & 4.6 & 8.1 & \\
\hline Daily family expense USD ( $n=155)$ & $3.3(3.0-3.6)$ & & $3.2(2.5-3.9)$ & & 0.4 \\
\hline Have a TV set & 120 & 80.5 & 29 & 50.9 & 0.01 \\
\hline Have a car & 5 & 3.4 & 1 & 1.8 & 0.8 \\
\hline Have a motorbike & 113 & 75.8 & 27 & 47.4 & 0.8 \\
\hline
\end{tabular}

Numbers and (percentages). Median and (interquartile range)

a 76 were "caregivers" from the orphanage

months. Median CD4 percentage did not differ between groups at initiation of ART (Table 2).

A total of 57 children were transferred to secondline ART within a median time of 36.5 (IQR 19.6-55.9) months. Children on second-line were more often double orphans $(p=0.06)$, aged over 7 years $(p=0.01)$ and living in orphanages than children in the first-line group. They had a significantly lower CD4 cell count at the last control.

First-line treatments began mostly with 3TC + D4T + NVP (62.9 \%) while ABC + DDI + LPV (54.4 \%) was the most frequent second-line regimen at the time of the survey. Full adherence to ART was self-reported for 226 children (97.4\%) and ascertained for 222 children (95.6\%) by counting pills at home or at the institution. No decrease in adherence was reported among children on second-line.

Overall, 18 (7.7 \%; 95 \% CI 4.6-11.9) showed a VF, 14 (8.6\%; $95 \%$ CI 4.8-14.0) under first-line and 4 (7.0\%;
$95 \%$ CI 1.9-17.0) under second-line ART ( $\mathrm{p}=0.5)$.A total of 155 families $(62.0 \%)$ reported breastfeeding $(61 ; 32.2 \%$ vs. $31 ; 49.2 ; \mathrm{p}=0.04)$. The mean duration of breastfeeding was 7.4 months (95\% CI 7.0-7.9). Families were unable to answer the question about HIV prophylaxis during pregnancy.

The mean global weight gain within the previous year of treatment was $3.7 \mathrm{~kg}$ (95\% CI 3.3-4.0) without difference between the groups $(3.8 \mathrm{~kg} ; 95 \%$ CI 3.4-4.1 and $3.3 \mathrm{~kg}$; $95 \%$ CI 2.0-4.5, p = 0.3, for first-line and secondline ART, respectively). The absence of weight gain over the previous year was not associated with VF. Of $6(2.5 \%)$ children with no weight gain, only one $(0.4 \%)$ had a VF.

In multivariate analysis, having the last CD4 percentage below $15 \%$ was the only factor associated with VF for children on first-line treatment (OR $44.995 \% \mathrm{CI}$ 10.2-196.2) and the second-line group (OR 69; $95 \% \mathrm{CI}$ 4.7-995) or when combining first and second-line group together (OR 40.4; 95 \% CI 11-134) (Table 3). 
Table 2 Treatment characteristics of children on first-line and second-line ART at National Pediatric Hospital

\begin{tabular}{|c|c|c|c|c|c|}
\hline & \multicolumn{2}{|l|}{ First-line } & \multicolumn{2}{|l|}{ Second-line } & \multirow[t]{2}{*}{$\mathrm{p}$} \\
\hline & $n=175$ & $\%$ & $n=57$ & $\%$ & \\
\hline \multicolumn{6}{|c|}{ Clinical status at ART onset } \\
\hline WHO Stage I & 37 & 21.1 & 5 & 8.8 & 0.06 \\
\hline WHO Stage II & 93 & 53.1 & 36 & 63.2 & \\
\hline WHO Stage III & 44 & 25.1 & 14 & 24.6 & \\
\hline WHO Stage IV & 1 & 0.6 & 2 & 3.5 & \\
\hline Initial CD4 cells (\%) & $9.1(3.9-12.9)$ & & $7.9(2.5-12.8)$ & & 0.1 \\
\hline Initial CD4 <15\% & 147 & 84.0 & 52 & 91.2 & 0.17 \\
\hline $\begin{array}{l}\text { Time before ART } \\
\text { onset (months) }\end{array}$ & $2.6(1.1-15.7)$ & & $2.5(1.2-8.3)$ & & 0.1 \\
\hline \multicolumn{6}{|l|}{ At the time of survey } \\
\hline $\begin{array}{l}\text { Time on ART } \\
\text { (months) }\end{array}$ & $\begin{array}{l}70.5(43.9- \\
90.8)\end{array}$ & & $\begin{array}{l}81.0(71.4- \\
92.5)\end{array}$ & & 0.001 \\
\hline $\begin{array}{l}\text { Time since switch } \\
\text { on second-line } \\
\text { (months) }\end{array}$ & NA & & $\begin{array}{l}36.5(19.6- \\
55.9)\end{array}$ & & \\
\hline $\begin{array}{l}\text { Time between } \\
\text { VL and survey } \\
\text { (months) }\end{array}$ & $0.1(0.1-4)$ & & $0.1(0.1-4)$ & & 0.7 \\
\hline $\begin{array}{l}\text { Non-adherence } \\
\text { to ART }\end{array}$ & 6 & 3.4 & 0 & & 0.1 \\
\hline $\begin{array}{l}\text { Weight gain over } \\
1 \text { year }(\mathrm{kg})\end{array}$ & $3.8(3.5-4.2)$ & & $3.5(2.7-4.2)$ & & 0.3 \\
\hline Last CD4 cells (\%) & $\begin{array}{l}27.8(23.6- \\
31.8)\end{array}$ & & $22(19.1-27)$ & & $<0.001$ \\
\hline CD4 cells $<15 \%$ & 2 & 1.1 & 6 & 10.5 & \\
\hline \multicolumn{6}{|c|}{ Initial first-line treatment } \\
\hline $3 T C+D 4 T+N V P$ & 93 & 53.1 & 53 & 93.0 & \\
\hline $3 T C+A Z T+N V P$ & 36 & 20.6 & & & \\
\hline $3 T C+D 4 T+E F V$ & 30 & 17.1 & 4 & 7.0 & \\
\hline $3 T C+A Z T+E F V$ & 14 & 8.0 & & & \\
\hline $3 T C+A Z T+L P V$ & 1 & 0.6 & & & \\
\hline $3 T C+D 4 T+L P V$ & 1 & 0.6 & & & \\
\hline \multicolumn{6}{|c|}{ Current second-line treatment } \\
\hline$A B C+D D I+L P V$ & & & 31 & 54.4 & \\
\hline $3 T C+T D F+L P V$ & & & 13 & 22.8 & \\
\hline $3 T C+D D I+L P V$ & & & 3 & 5.3 & \\
\hline $3 T C+A Z T+L P V$ & & & 3 & 5.3 & \\
\hline$A B C+T D F+L P V$ & & & 3 & 5.3 & \\
\hline $3 T C+A B C+L P V$ & & & 2 & 3.5 & \\
\hline $3 T C+A Z T+L P V$ & & & 2 & 3.5 & \\
\hline
\end{tabular}

Numbers and (percentages). Median and (interquartile range)

$\mathrm{Cl}$ Confidence interval

\section{Discussion}

Early studies on ART in Cambodia demonstrated high effectiveness both in adults and children with follow-up ranging from 12 months to 4 years [13-15, 23-28]. At that time, reports about children's ART chiefly expressed concerns about the challenges of detecting treatment

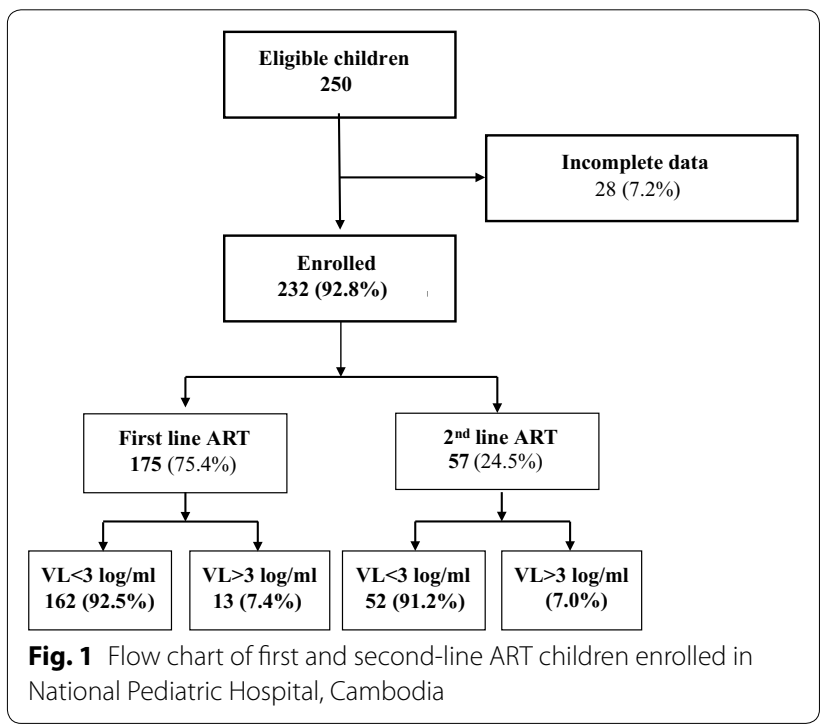

failures using only immunological and clinical criteria [16]. Later, with the development of HIV genotypic resistance testing, high resistance mutations were reported in children with virological failure on first-line ART [17, 18]. However this testing was not yet routinely available. Our study confirms the global effectiveness of both first-line and second-line regimens for children over a long duration of follow-up (73 months), and a high level of adherence evidenced by routine tools. Second-line children who previously failed the first ART line had a similar rate of VF as children on first-line treatment. Despite these good results, a crucial issue for children with VF on second-line treatment is the lack of further options for ART in Cambodia and other countries. Besides, children on the second-line regimen had a lower median CD4 percentage at the last check. Improved measurements of adherence and access to genotypic testing for drug resistance, are urgently needed to provide high risk children with the best treatment options.

Our study confirms a high level of adherence among children currently on ART using the routine tools. Children on second-line, previously described as poorly adherent, now appear to be fully compliant with treatment. Such improvement was probably due to the implementation of home visits, called home-based care (but this issue was not documented in the survey), and the careful attention that was paid to adherence during all routine visits at the hospital. The second reason for improved adherence was probably that half of children live in orphanages which are commited to supporting adherence to ART and to routine medical follow-up. However, these good adherence results could be questioned given the occurrence of VF among children on second-line ART. The quality of adherence was probably 


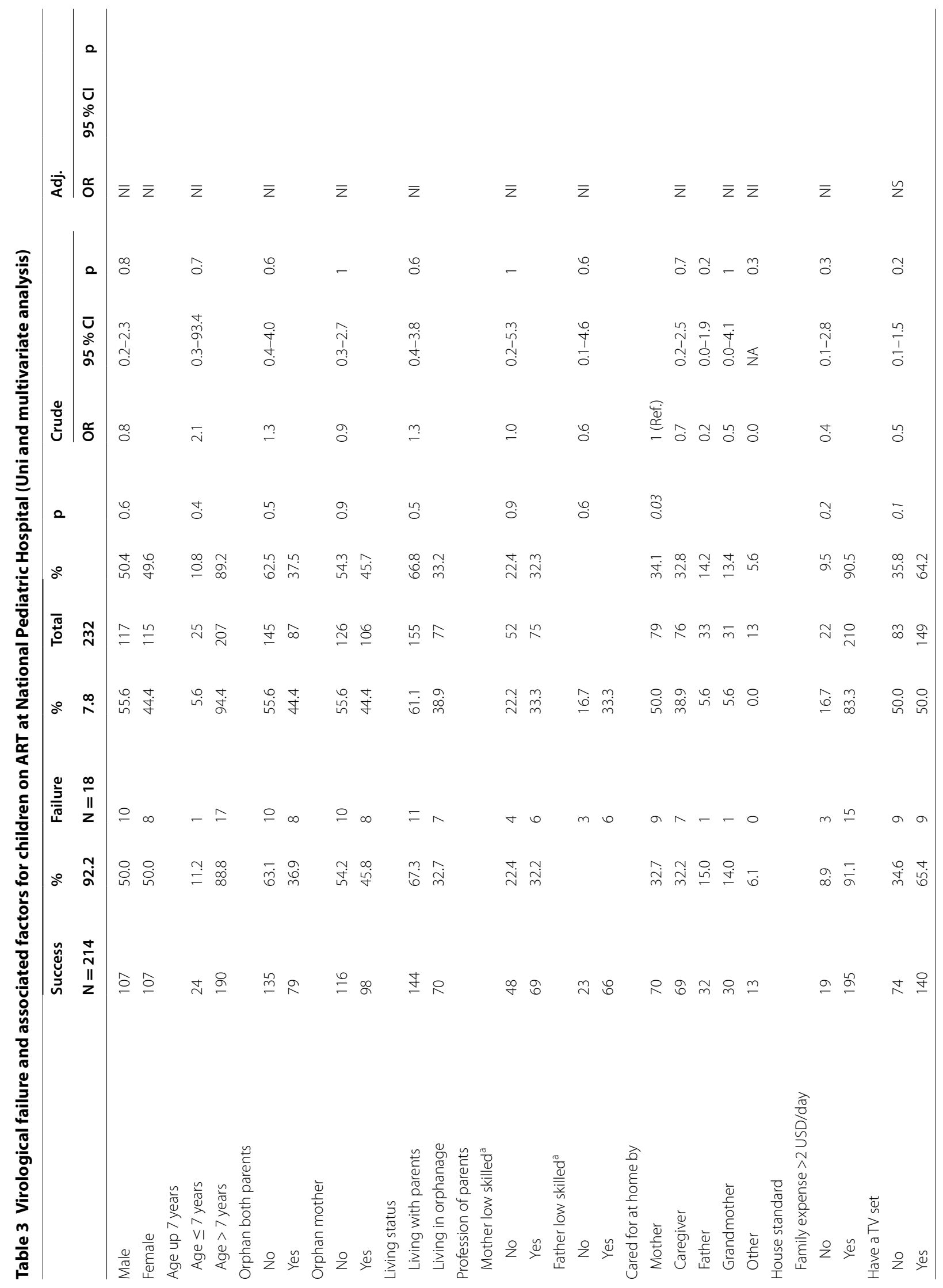


Barennes et al. BMC Res Notes (2016) 9:69

Page 7 of 10

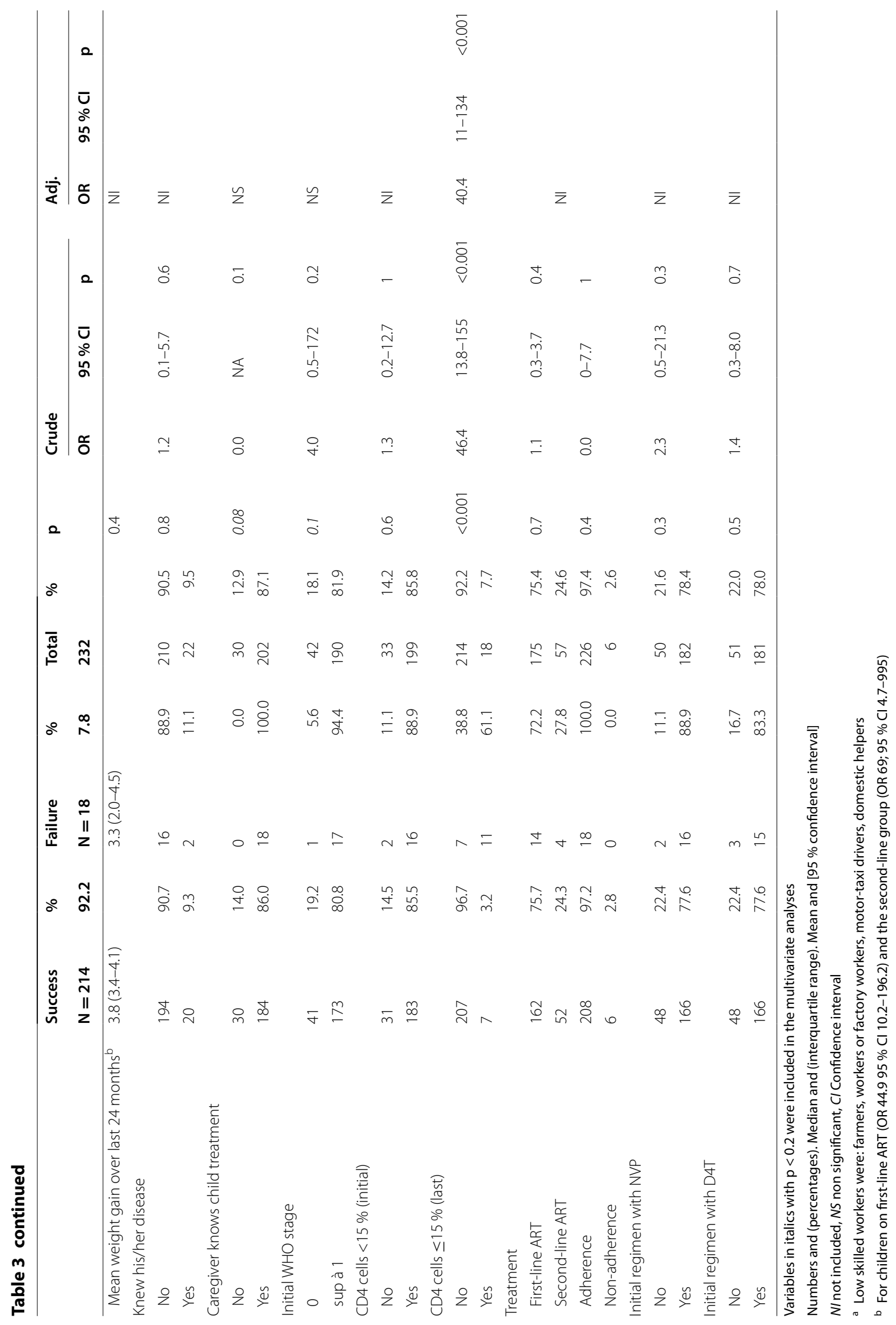


overestimated using the routine tools (self reporting and pill counting during home visits). Health staff and the investigation team reported that parents/caregivers, being informed in advance about visits, prepared and presented to the health worker the expected number of pills. The precise reasons were not documented but could have been the fear of reprimands or that treatment would be discontinued or changed. Similar observations were reported in Ethiopia where routine adherence rates in the preceding 7 days decreased from 93.3 to $34.8 \%$ using unannounced home-based pill counts [29]. Due to ethical concerns and fear of stigmatization [20], conducting unannounced visits was considered inappropriate by our study team.

With the 18 children who experienced a VF, it was not possible to quantify the rate of resistance to antiretroviral drugs since genotyping tests were not available, a limitation of our study. However, other studies provided information regarding HIV mutations among children with VF during the same period. Between December 2004 and January 2011, in Cambodia, all genotypic tests for HIV drug resistance mandated by the provincial capital were conducted at the Pasteur Institute. Assuming a lower threshold of VF (viral load $\geq 250$ copies $/ \mathrm{mL}$ ), genotypic testing performed on 233 children revealed that 33 (14.1\%) harboured the Q151M and 17 (7.2 \%) the K65R mutations which confer resistance to a large range of nucleoside reverse transcriptase inhibitors (NRTIs) [17]. This trend was confirmed by a similar study conducted at the Angkor Hospital for Children in Siem Reap [18]. Of 51 viremic children (>1000 copies/mL) all but one harbored drug resistance mutations to NRTIs and nonnucleoside reverse transcriptase inhibitors (NNRTIs), and half had more than 4 mutations. A quarter had multi-resistant mutations and 9 (18\%) high-level resistance-predicting mutations to subsequent therapy options including didanosine (DDI), abacavir (ABC), etravirine (ETR), and tenofovir (TDF) [18]. Emergence of these mutations is a critical issue in resource-limited settings where NRTI molecules available for second-line regimens remain limited.

The continuation of failing ART regimens is of concern since it will result in an accumulation of resistance that will hamper the effectiveness of subsequent regimens. The scaling up of drug resistance testing has been proposed $[18,28,30]$.

Among the children who attended the HIV clinic, the percentage living in orphanages increased from $10 \%$ in 2007 up to $32.2 \%$ in 2013 [20]. In our study, the number of orphans tended to be higher among children on second-line regimens. Being an orphan was previously associated with more frequent VF [31] and subsequent transition to second-line ART. In our study, being cared for by one's mother was a non-protective factor for VF in univariate analysis. This was probably related to the difficult situation of the families living with HIV, the majority of whom are living in extreme poverty (Table 1). So, the best way to improve ART success would probably be to improve the economic and social conditions of those living with HIV. This is supported by the protective factor (having a TV set) identified in univariate analysis, suggesting better access to information, prevention and care.

Effective interventions to reduce poverty are critical in mitigating the negative impacts of HIV and AIDS on children and households [32].

\section{Limitations}

This study has several limitations. The first limitation is the small sample size due to time and budget constraints. The second limitation was the fact that the number and frequency of VL done per child, that could have affected the results, could not be addressed. However health staff were following the national guidelines on VL, which probably may have reduce this limitation. The third limitation was inability to conduct drug resistance tests as they were not covered by the ART program. Improving adherence support and availability of drug resistance testing are crucial to halt the rise in resistance mutations to ART drugs available in Cambodia.

\section{Conclusions}

Children on second-line are more often double orphans, aged over 7 years and living in orphanages than children in the first-line ART in the National Pediatric hospital of Cambodia. The pattern of risk factors for VF is changing in Cambodia. The prevention of VF requires improving ART adherence and monitoring, better monitoring of children with low CD4 counts and access to routine viral load testing. Attention is needed to conflicting results of adherence and viral failure. The presence of VF in children under second-line ART is a crucial issue in a country where no third line ART is available.

\section{Additional files}

Additional file 1. Questionnaire used during the survey.

Additional file 2. STROBE check list.

\section{Abbreviations}

ART: antiretroviral therapy; Cl: confidence interval; HIV: human immunodeficiency virus; HIV DR: HIV drug resistance; IFMT: Institut de la Francophonie pour la Médecine Tropicale; IQR: inter quartile range; OR: odds ratio; NPH: National Pediatric Hospital; NCHADS: National Center for HIV/AIDS, Dermatology and STD, Sexual Transmissible Disease; NI: not included; NS: non significant; VF: virological failure; VL: plasma HIV-1 viral Load; DDI: didanosine; ABC: abacavir; ETR: etravirine; TDF: tenofovir. 


\section{Authors' contributions}

$\mathrm{HB}$ conceived the survey, coordinated data acquisition with substantial contribution from KV and UV, conducted the analysis and interpretation of the data and wrote the manuscript. KV conducted the data collection, and made the primary analysis and report with $\mathrm{HB}$ and UV contributions. YB and MS participated to the design and follow up of the survey, and made substantial comments on the manuscripts. FR provided inputs for the analysis and substantial comments on the manuscripts. All authors contributed to the writing of the paper. All authors read and approved the final manuscript.

\section{Author details}

${ }^{1}$ Agence Nationale de Recherche sur le VIH et les Hépatites, Preah Monyvong Blvd, Phnom Penh, Cambodia. ${ }^{2}$ Institut de la Francophonie pour la Médecine Tropicale, Vientiane, Lao People's Democratic Republic. ${ }^{3}$ ISPED, Centre INSERM U897-Epidemiologie-Biostatistique, Univ. Bordeaux, 33000 Bordeaux, France. ${ }^{4}$ Epidemiology Unit, Pasteur Institute, Phnom Penh, Cambodia. ${ }^{5}$ Virological Unit, Pasteur Institute, Phnom Penh, Cambodia. ${ }^{6}$ University of Health Science, Phnom Penh, Cambodia.

\section{Acknowledgements}

This work was part of a master's study (KV) by "Institut Francophone pour la Médecine Tropicale" (IFMT, Vientiane, Laos). We thank IFMT teachers for their help and Pr M Strobel for comments. We thank the National Pediatric Hospital staff in Cambodia for their support. We thank all the families and children and people who participated in the surveys. We thank P Aaron and M Grippenberg for kind editing. We thank Leila Srour for helpful advices and final edit. IFMT, the funding agency, had no role in the decision of preparing, analyzing and publishing the paper. Opinions expressed in the paper do not represent the opinion of funding agency.

\section{Competing interests}

The authors declare that they have no competing interests.

Received: 1 July 2015 Accepted: 22 January 2016 Published online: 05 February 2016

\section{References}

1. WHO. UNAIDS. Global summary of the AIDS epidemic. 2012. http://www. unaids.org/sites/default/files/en/media/unaids/contentassets/documents/epidemiology/2013/gr2013/201309_epi_core_en.pdf. Accessed 20 Jan 2015.

2. Arage G, Tessema GA, Kassa H. Adherence to antiretroviral therapy and its associated factors among children at South Wollo Zone Hospitals, Northeast Ethiopia: a cross-sectional study. BMC Public Health. 2014. doi:10.1186/1471-2458-14-365.

3. WHO. Global update on HIV treatment 2013: results and opportunities. www.who.int/iris/bitstream/10665/85326/1/9789241505734_eng.pdf. Accessed 20 Jan 2015.

4. Penazzato M, Revill P, Prendergast AJ, Collins IJ, Walker S, Elyanu PJ, et al. Early infant diagnosis of HIV infection in low-income and middle-income countries: does one size fit all? Lancet Infect Dis. 2014;14(7):650-5.

5. Ciaranello AL, Chang Y, Margulis AV, Bernstein A, Bassett IV, Losina $E$, et al. Effectiveness of pediatric antiretroviral therapy in resourcelimited settings:a systematic review and meta-analysis. Clin Infect Dis. 2009;49:1915-27.

6. Rojas SP, Holguin A. Drug resistance in the HIV-1-infected paediatric population worldwide:a systematic review. J Antimicrob Chemother. 2014;69:2032-42.

7. Mutwa PR, Boer KR, Rusine J, Muganga N, Tuyishimire D, Schuurman R, et al. Long-term effectiveness of combination antiretroviral therapy and prevalence of HIV drug resistance in HIV-1-infected children and adolescents in Rwanda. Pediatr Infect Dis. 2014;33:63-9.

8. Ruel TD, Kamya MR, Li P, Pasutti W, Charlebois ED, Liegler T, et al. Early virologic failure and the development of antiretroviral drug resistance mutations in HIV-infected Ugandan children. J Acquir Immune Defic Syndr. 2011;56:44-50.
9. NCHADS, Chhea Chhorvann, Saphonn Vonthanak Estimations and Projections of HIV/AIDS in Cambodia 2010-2015. 2011. http://www.nchads. org/Publication/HSS/Estimations\%20and\%20Projections\%20of\%20HIVAIDS\%20in\%20Cambodia\%202010-2015_eng.pdf. Accessed 20 Jan 2015.

10. NCHADS. Conceptual Framework for Elimination of New HIV infections in Cambodia by 2020. 2011. http://www.nchads.org/Events/000184/ planning_workshop_for_2013/nchads/Cambodia\%203\%200\%20by\%20 2020\%20-September\%202012.pdf. Accessed 20 Jan 2015.

11. NCHADS. Fourth quaterly report 2012. 2013. http://www.nchads.org/ Report/q4_2012_compr_report\%20en.pdf. Accessed 20 Jan 2015.

12. NCHADS. Annual report 2013. 2014. http://www.nchads.org/Report/ annual_report_2013_eng.pdf. Accessed 20 Jan 2015.

13. Janssens B, Raleigh B, Soeung S, Akao K, Te V, Gupta J, et al. Effectiveness of highly active antiretroviral therapy in HIV-positive children:evaluation at 12 months in a routine program in Cambodia. Pediatrics. 2007;120:e1134-40

14. Isaakidis P, Raguenaud ME, Te V, Tray CS, Akao K, Kumar V, et al. High survival and treatment success sustained after two and three years of first-line ART for children in Cambodia. J Int AIDS Soc. 2010. doi:10.1186/1758-2652-13-11.

15. Raguenaud ME, Isaakidis P, Zachariah R, Te V, Soeung S, Akao K, et al. Excellent outcomes among HIV + children on ART, but unacceptably high pre-ART mortality and losses to follow-up:a cohort study from Cambodia. BMC Pediatr. 2009. doi:10.1186/1471-2431-9-54.

16. Westley BP, DeLong AK, Tray CS, Sophearin D, Dufort EM, Nerrienet E, et al. Prediction of treatment failure using 2010 World Health Organization Guidelines is associated with high misclassification rates and drug resistance among HIV-infected Cambodian children. Clin Infect Dis. 2012;55:432-40.

17. Nouhin J, Madec Y, Ngo-Giang-Huong N, Ferradini L, Nerrienet E. Increased Risk of Q151 M and K65R Mutations in Patients Failing Stavudine-Containing First-line Antiretroviral Therapy in Cambodia. PLoS One. 2013;8:e73744

18. Coetzer M, Westley B, Delong A, Tray C, Sophearin D, Nerrienet E, et al. Extensive drug resistance in HIV-infected Cambodian children who are undetected as failing first-line antiretroviral therapy by WHO 2010 guidelines. AIDS Res Hum Retroviruses. 2013;29:985-92.

19. National Center for HIV/AIDS DaSTDN National guidelines for the use of pediatric antiretroviral therapy in Cambodia.2011. http://www.nchads.org/ Guideline/NGTreatment_art_children_eng.pdf. Accessed 20 Jan 2015.

20. Barennes H, Tat S, Reinharz D, Vibol U. Perceived stigma by children on antiretroviral treatmentin Cambodia. BMC Pediatr. 2014. doi:10.1186/ s12887-014-0300-9.

21. WHO Consolidated guidelines on the use of antiretroviral drugs for treating and preventing HIV infection. 2013. http://www.who.int/hiv/pub/ guidelines/arv2013/download/en/. Accessed 20 Jan 2015

22. WHO Antiretroviral therapy for HIV infection in infants and children:recommendations for a public health approach, 2010 revision. 2010. http://www.who.int/hiv/pub/paediatric/infants2010/en/. Accessed 20 Jan 2015.

23. Segeral O, Limsreng S, Nouhin J, Hak C, Ngin S, De LM, et al. Three years follow-up of first-line antiretroviral therapy in cambodia:negative impact of prior antiretroviral treatment. AIDS Res Hum Retroviruses. 2011;27:597-603.

24. Sophan S, Meng CY, Pean P, Harwell J, Hutton E, Trzmielina S, et al. Virologic and immunologic outcomes in HIV-infected Cambodian children after 18 months of highly active antiretroviral therapy. Southeast Asian J Trop Med Public Health. 2010;41:126-37.

25. Ferradini L, Laureillard D, Prak N, Ngeth C, Fernandez M, Pinoges L, et al. Positive outcomes of HAART at 24 months in HIV-infected patients in Cambodia. AIDS. 2007;21:2293-301.

26. Ferradini L, OukV, Segeral O, Nouhin J, Dulioust A, Hak C, et al. High efficacy of lopinavir/r-based second-line antiretroviral treatment after 24 months of follow up at ESTHER/Calmette Hospital in Phnom Penh. Cambodia. J Int AIDS Soc. 2011;14:14.

27. Morineau G, Vun MC, Barennes H, Wolf RC, Song N, Prybylski D, et al. Survival and quality of life among HIV-positive people on antiretrovira therapy in Cambodia. AIDS Patient Care STDS. 2009;23:669-77.

28. Pujades-Rodriguez M, Schramm B, Som L, Nerrienet E, Narom P, Chanchhaya $\mathrm{N}$, et al. Immunovirological outcomes and resistance patterns at 
4 years of antiretroviral therapy use in HIV-infected patients in Cambodia. Trop Med Int Health. 2011;16:205-13.

29. Zolfo M, Schapiro JM, Phan V, Koole O, Thai S, Vekemans M, et al. Genotypic impact of prolonged detectable HIV type 1 RNA viral load after HAART failure in a CRF01_AE-infected cohort. AIDS Res Hum Retroviruses. 2011:27:727-35.

30. Biressaw S, Abegaz WE, Abebe M, Taye WA, Belay M. Adherence to Antiretroviral Therapy and associated factors among HIV infected children in Ethiopia: unannounced home-based pill count versus caregivers' report. BMC Pediatr. 2013;13:132.
31. Kikuchi K, Poudel KC, Muganda J, Majyambere A, Otsuka K, Sato T, et al. High risk of ART non-adherence and delay of ART initiation among HIV positive double orphans in Kigali, Rwanda. PLoS One. 2012;7:e41998.

32. Franco LM, Burkhalter B, de WA, Jennings L, Kelley AG, Hammink ME. Evidence base for children affected by HIV and AIDS in low prevalence and concentrated epidemic countries: applicability to programming guidance from high prevalence countries. AIDS Care. 2009;21(Suppl 1):49-59.
Submit your next manuscript to BioMed Central and we will help you at every step:

- We accept pre-submission inquiries

- Our selector tool helps you to find the most relevant journal

- We provide round the clock customer support

- Convenient online submission

- Thorough peer review

- Inclusion in PubMed and all major indexing services

- Maximum visibility for your research

Submit your manuscript at www.biomedcentral.com/submit
(O) BioMed Central 